Journal of Environmental Impact Assessment, Vol. 22, No. 4(2013) pp.361 367

http://dx.doi.org/10.14249/eia.2013.22.4.361

\title{
연구논문
}

\author{
공사장 방음시설 설치기준 개선방안에 관한 연구 \\ 박영민 · 김경민 \\ 한국환경정책 · 평가연구원 \\ (2013년 7월 4일 접수, 2013년 7월 31일 승인)
}

\section{A study on the improvement for installation guide of soundproofing facilities in construction site}

\section{Young-Min Park · Kyoung-Min Kim}

Korea Environment Institute

(Manuscript received 4 July 2013; accepted 31 July 2013)

\begin{abstract}
Noise and vibration occurs during construction intermittently, but with the most arise complaints. There is a need to efficiently manage the construction noise and vibration problems because in case a residential facility that requires calmness around the construction site adversely affects the living conditions of nearby residents. The ministry of environment has mandating the installation of soundproofing facilities for the management of construction noise. In order to enforce a particular construction, the mandatory install with soundproofing facilities before the start of construction, and after construction. However, Installation guide of soundproofing facilities for construction sites were not considered affected areas by noise and there is no provision of performance evaluation for soundproofing facilities.

In this study, investigated the status and problems of the installation guide for soundproofing facilities in construction sites, we propose an efficient installation guide of soundproofing facilities for the reduction construction noise.
\end{abstract}

Keywords : Construction noise, Soundproofing facilities, Installation guide

\section{I. 서 론}

공사장 소음 · 진동은 공사기간 내에만 발생하고, 다른 소음 · 진동과 같이 지속적이지는 않으나 공사 기간 중 가장 많은 민원을 발생하는 특징을 가지고
있다. 특히 공사장 주변에 주거시설 등 정온함이 요 구되는 시설이 있는 경우 인근 주민의 생활환경에 많 은 악영향을 미치기 때문에 공사장 소음·진동 문제 를 효율적으로 관리할 필요가 있다(환경부, 2006). 환경부는 공사장 소음관리를 위한 조치방안의 하

Corresponding Author: Young-Min Park, Kyoung-Min Kim, Jinheungno 215, Eunpyeong-gu, Seoul, Korea Tel: 82-2-380-7676 Fax: 82-2-380-7744 E-mail: ympark@kei.re.kr,kmkim@kei.re.kr 
나로 공사장 방음시설 설치를 의무화하고 있다. 이는 공사장 인근 주민의 소음피해 민원을 해소시키기 위 해 생활소음 - 진동이 발생할 우려가 있는 공사로서 주거지역 등에서 환경부령으로 정하는 특정공사를 시행하고자 하는 자는 공사개시 전 방음시설을 의무 적으로 설치한 후에 공사를 개시해야 한다. 여기서, 방음시설은 소음원과 그 영향을 받는 부분 사이에 설 치하여 소음저감효과를 유발하는 모든 차폐물을 말 한다. 방음시설의 소음저감효과는 방음시설의 설치 규모에 의한 회절감쇠와 방음시설의 재질 자체의 투 과손실 등이 종합적으로 영향을 미치게 된다(김하근, 2010).

하지만, 공사장에 적용되고 있는 방음시설 설치를 위한 기준은 소음피해지역이 고려되지 않고 있으며 방음시설에 대한 성능평가 규정조차 마련되어 있지 않아 이에 대한 대책마련이 필요하겠다.

본 연구에서는 공사장 방음시설 설치기준에 대한 현황파악 및 문제점 고찰을 통해 공사장 소음저감에 실효성있는 방음시설 설치기준 개선방안을 제안하고 자 한다.

\section{II. 공사장 방음시설 설치기준 현황 및 문제점 고찰}

\section{1. 공사장 방음시설 설치기준 현황}

공사장 방음시설의 설치기준은 특정공사에 한하여 적용되며, 환경부(2009)의「소음 · 진동 관리법 시행 규칙」제 21 조 제 6 항과 관련하여 〈별표 10〉에 제시되 어 있으며 Table 1과 같다. 여기서, 특정공사란 항타 기 · 항발기, 공기압축기 등의 장비를 5 일 이상 사용 하는 공사나 연면적이 $1,000 \mathrm{~m}^{2}$ 이상인 건축물의 건축 공사 및 연면적이 $3,000 \mathrm{~m}^{2}$ 이상인 건축물의 해체공 사 등이다. 또한 방음시설 설치기준과 관련된 규정으 로 환경부(2009)의「소음 · 진동관리법」제 40 조 “방 음시설의 성능과 설치기준 등”과 Table 2에 제시한 환경부(2011) 고시 제2011-135호 「방음시설의 성능 및 설치기준」이 있다. 환경부 고시 제2011-135호의 2조 적용범위에서는 "이 기준은 교통소음 저감을 목
Table 1. Installation guide of construction sound proofing facilities

1. 방음벽시설 전후의 소음도 차이(삽입손실)는 최소 $7 \mathrm{~dB}$ 이상 되어야 하며 높이는 $3 \mathrm{~m}$ 이상 되어야 한다.

2. 공사장 인접지역에 고층건물 등이 위치하고 있어 방음 벽시설로 인한 음의 반사피해가 우려되는 경우에는 흡 음형 방음벽시설을 설치하여야 한다.

3 4. 생략

참고

1. 삽입손실 측정을 위한 측정지점은 음원으로부터 $5 \mathrm{~m}$ 이 상 떨어진 노면 위 $1.2 \mathrm{~m}$ 지점으로 하고, 방음벽시설로 부터 $2 \mathrm{~m}$ 이상 떨어져야 하며, 동일한 음량과 음원을 사 용하는 경우에는 기준위치(reference position)의 측정 은 생략 할 수 있다.

2. 생략

Source: Noise and vibration control act. Enforce Rules(2009)

Table 2. Performance and installation guide of construction soundproofing facilities

제 1 조, 제 3 조 제 5 조, 제 7 조 제 11 조, 제 13 조, 제 14 조 이 하 생략

제 2 조(적용범위) 이 기준은 교통소음 저감을 목적으로 설 치되는 방음시설의 설치 및 유지관리에 적용하며, 공장소음 · 공사장소음 기타 생활소음 저감시설의 설치 및 유지관리에 준용할 수 있다.

제6조(투과손실) (1)방음시설의 방음판 투과손실은 수음자 위치에서 기대하는 회절감쇠치에 $10 \mathrm{~dB}$ 을 더한 값 이 상으로 하거나, $500 \mathrm{~Hz}$ 의 음에 대하여 $25 \mathrm{~dB}$ 이상, $1000 \mathrm{~Hz}$ 의 음에 대하여 $30 \mathrm{~dB}$ 이상을 표준으로 한다. 제 12 조(수음점 결정) 수음점은 보호대상지역 부지경계선 중 소음도가 소음저감 목표기준을 초과하는 지점으 로 한다. 다만, 소음으로부터 보호받아야 할 시설 이 2 층 이상인 경우 등 부지경계선보다 소음도가 더 큰 장소가 있는 경우에는 그 곳에서 소음원 방향 으로 창문 · 출입문 또는 건물벽 밖의 $0.5 \mathrm{~m}$ 내지 $1 \mathrm{~m}$ 떨어진 지점으로 한다.

Source: Ministry of Environment Act(2011-135).

적으로 설치되는 방음시설의 설치 및 유지관리에 적 용하며, 공장소음 · 공사장소음, 기타 생활소음 저감 시설의 설치 및 유지관리에 준용할 수 있다.”로 명기 되어 공사장 등의 소음저감시설 설치 시에도 그 기준 을 사용할 수 있도록 하고 있다.

\section{2. 방음시설 설치기준 문제점}

「소음 - 진동관리법 시행규칙」에서 규정하고 있는 공사장 방음시설 설치기준의 문제점을 간단하게 정 리하면 Table 3 과 같다.

「소음 · 진동관리법 시행규칙」〈별표 10〉의 공사장 방음시설 설치기준 제 1항에 제시된 "방음벽시설 전 후의 소음도 차이(삽입손실)는 최소 $7 \mathrm{~dB}$ 이상 되어 
Table 3. Problem of installation guide for construction soundproofing facilities

\begin{tabular}{|c|c|c|}
\hline [별표 10] 내용 & 문제점 & 비 고 \\
\hline $\begin{array}{l}\text { 1항 "방음벽시설 } 3 \mathrm{~m} \text { 이상 되어야 } \\
\text { 한다." }\end{array}$ & $\begin{array}{l}\text { 노면에서는 삽입손실치 } 7 \mathrm{~dB} \text { 기준을 만족하더 } \\
\text { 라도 고층의 정온시설에서는 만족하지 않는다. }\end{array}$ & \\
\hline $\begin{array}{l}\text { 2항 “공사장 인접지역에 방음벽 } \\
\text { 시설을 설치하여야 한다.” }\end{array}$ & $\begin{array}{l}\text { 측정지점을 소음 피해지역으로 명시하고 있지 } \\
\text { 않아 기준을 충족해도 소음피해를 보는 경우가 } \\
\text { 있다. }\end{array}$ & \\
\hline $\begin{array}{l}\text { 참고 } 1 \text { “삽입손실 측정을 위한 } \\
\sim 2 \mathrm{~m} \text { 이상 떨어져야 하며 " }\end{array}$ & $\begin{array}{l}\text { 측정지점을 명시한 별표 조건을 충족하기 위해 } \\
3 \mathrm{~m} \text { 정도의 방음벽만 설치하면 된다. 피해지점 } \\
\text { 에서 삽입손실치를 측정하고 예상해야 소음피 } \\
\text { 해를 줄일 수 있다. }\end{array}$ & \\
\hline- & $\begin{array}{l}\text { 방음벽 설치 시 성능에 영향을 주는 투과손실 } \\
\text { 기준에 대한 규정이 없다. }\end{array}$ & $\begin{array}{l}\text { 교통소음관리 시 사용하는 환경부고시에 } \\
\text { 는 있다. (방음시설의 성능 및 설치기준) }\end{array}$ \\
\hline- & 설계 및 성능평가에 대한 규정이 없다. & \\
\hline
\end{tabular}

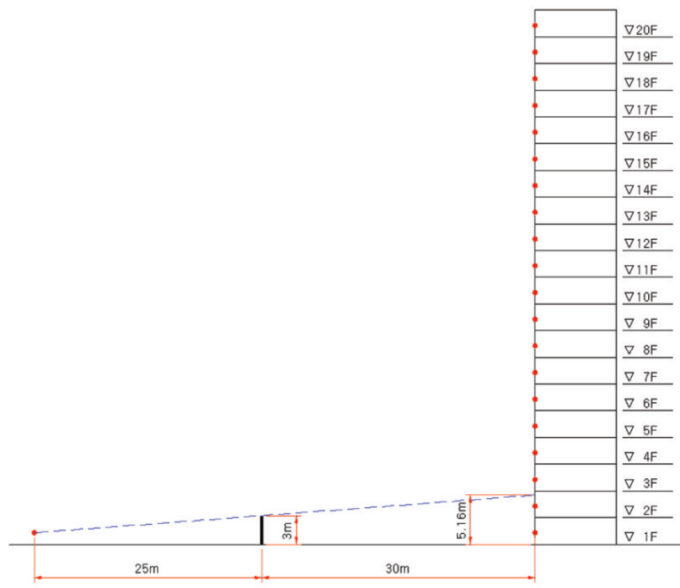

(a) Noise barrier height: $3 \mathrm{~m}$

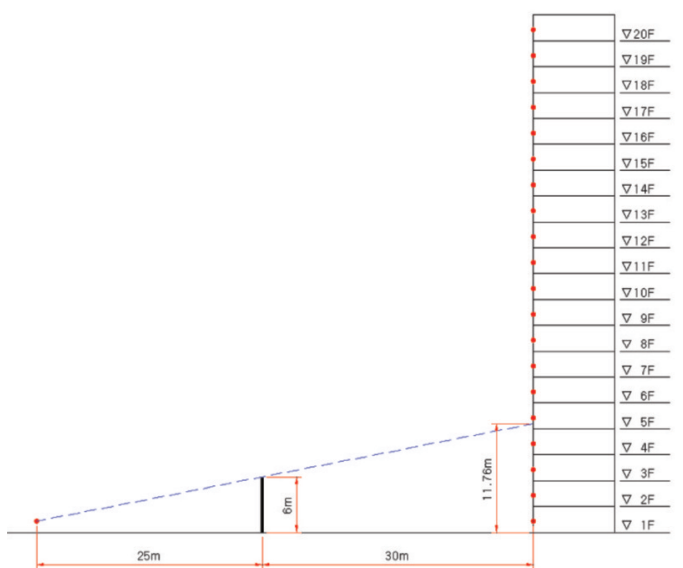

(b) Noise barrier height: $6 \mathrm{~m}$

Figure 1. Line of sight along the distance and noise barrier height

야 하며, 높이는 $3 \mathrm{~m}$ 이상 되어야 한다.”의 항목은 다 음과 같은 문제가 있다.

방음벽의 삽입손실치는 높이와 연장길이에 의한 회절감쇠치와 방음판넬의 투과손실치에 의해 결정된 다. 현재의 방음벽시설 기준과 같이 노면에서 $7 \mathrm{~dB}$ 의 삽입손실을 만족하더라도 고층의 정온시설이 위치할 경우를 가정하면 방음벽 높이를 $6 \mathrm{~m}$ 이상으로 하여도 고층의 정온시설(수음점)에서 삽입손실치 $7 \mathrm{~dB}$ 을 만 족하기 어렵다. 즉, 노면위에서의 방음벽시설기준을 만족하더라도 고층의 정온시설이 존재할 경우 이에 대한 저감대책이 없어 고층의 정온시설에 사는 주민 에게 피해가 있을 수 있다. Figure 1은 공사장의 소 음원에서 전달되는 소음의 삽입손실치 계산사례를 통해 현행 방음시설 기준이 고층의 정온시설에 불리
하도록 되어 있다는 것을 도면과 계산결과를 통해 제 시한 그림이다. Figure 1에서 파선은 가시선으로 아 파트에서 방음벽위로 소음원을 볼 수 있는 높이를 나 타내며, 가시선에 만나는 지점에서의 삽입손실치는 약 $5 \mathrm{~dB}$ 이다. 가정조건으로 제시한 $3 \mathrm{~m}$ 높이의 방음 벽일 때는 2 층에 가시선이 있으며, $6 \mathrm{~m}$ 높이일 때는 4 층에 가시선이 만나는 것을 확인할 수 있다. 방음벽 과 수음점의 이격거리는 $30 \mathrm{~m}$ 로 계산하였으며, 실제 도심지의 공사장은 이보다 이격거리가 훨씬 가까운 현장도 많다. 삽입손실치는 $3 \mathrm{~m}$ 높이의 방음벽의 경 우 1 층에서 $6.4 \mathrm{~dB}, 2$ 층에서 $5.6 \mathrm{~dB}$ 이며, $6 \mathrm{~m}$ 높이의 방음벽일 때는 1 층에서 $11.1 \mathrm{~dB}, 2$ 층에서 $10.4 \mathrm{~dB}, 3$ 층에서 $8.5 \mathrm{~dB}, 4$ 층에서 $6.8 \mathrm{~dB}$ 이다. 즉, 1 층에서 방 음벽 시설기준 $7 \mathrm{~dB}$ 을 만족하더라도 고층으로 올라갈 


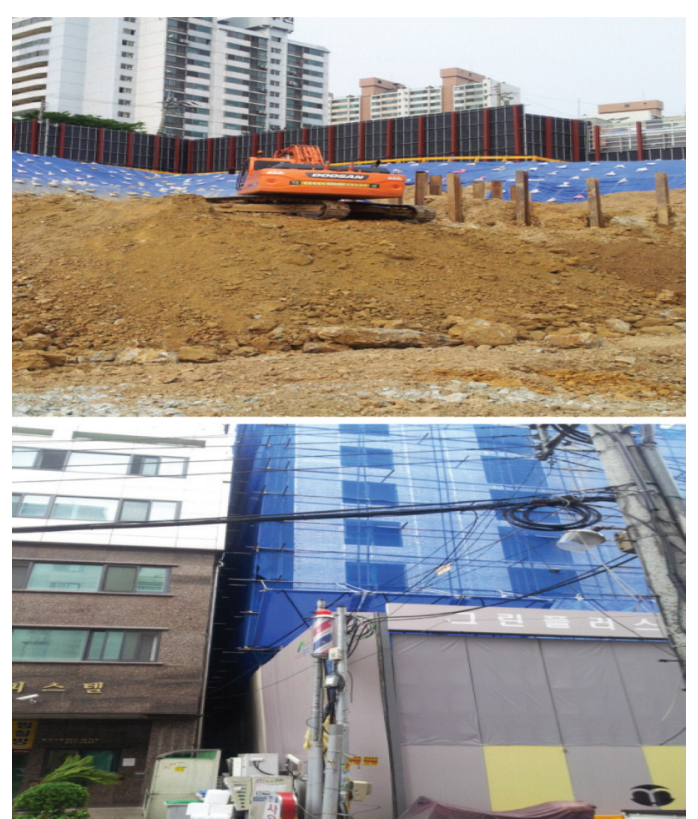

Figure 2. Position of noise barrier and receiver in city construction sites

수록 만족하지 못하는 경우가 있어 소음이 우려되는 고층을 수음점으로 정하여 환경목표기준을 만족할 수 있도록 하여야 한다.

방음벽의 삽입손실 계산방법은 다음과 같다(정일 록 등, 2012).

- Fresnel Number(N)의 계산

$N=\frac{\delta}{\lambda / 2}=\frac{2 \delta}{\lambda}=\frac{\delta f}{170}$

(직접음) $N_{1}=\delta_{1} \times \frac{f}{170}, \delta_{1}=\left(A+B_{1}\right)-d_{1}$

(반사음) $N_{2}=\delta_{2} \times \frac{f}{170}, \delta_{2}=\left(A+B_{2}\right)-d_{2}$

여기서 $\delta_{1}, \delta_{2}$ : 음원과 수음점 사이의 경로차

$A$ : 소음원에서 방음벽의 정점까지의 거리

$B_{1}, B_{2}$ : 방음벽의 정점에서 수음점까지의 거리

$d_{1}, d_{2}$ : 소음원에서 수음점까지의 직선거리

$f$. 대상음의 회절주파수 $(\mathrm{Hz})$

$\lambda:$ 음의 파장 $(=C / f, C \fallingdotseq 340 \mathrm{~m} / \mathrm{s})$

- Fresnel number $(N)$ 의 범위에 따른 회절감쇠치

$$
\begin{aligned}
L_{d^{d}} & =7.5+(0.6 \times \log N), & & 0<N \leq 0.1 \\
& =10+(3 \times \log N), & & 0.1<N \leq 0.8 \\
& =11+(7 \times \log N), & & 0.8<N \leq 30 \\
& =12+(6 \times \log N), & & 30<N \leq 60 \\
& =22, & & 60<N
\end{aligned}
$$

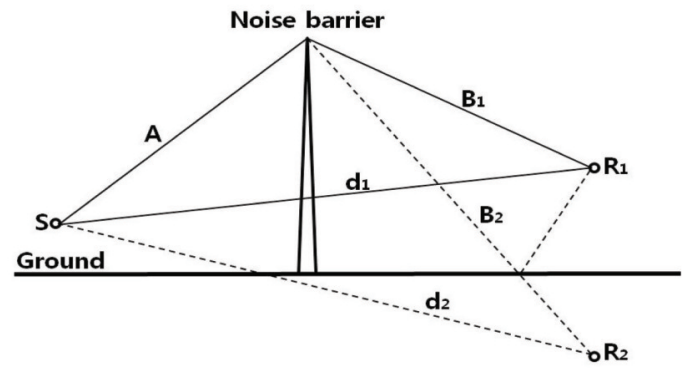

Figure 3. Diffraction loss of noise barrier

여기서, $L_{d}$ : 직접음과 반사음의 회절감쇠치

$N$ : 직접음과 반사음의 Fresnel number

- 회절감쇠치 $\left(\Delta L_{d}\right)$ 산정

$\Delta L_{d}=-10 \times \log \left(10^{-\frac{L_{n}}{10}}+10^{-\frac{L_{n}}{10}}\right) d B$

여기서,

$L_{d 1}, L_{d 2}$ : 직접음과 반사음에 대한 회절감쇠치

- 방음벽에 의한 소음감쇠효과(삽입손실치)

$\Delta L_{I}=-10 \log \left(10^{-\frac{\Delta L_{d}}{10}}+10^{-\frac{T L}{10}}\right)[\mathrm{dB}]$

여기서,

$\Delta L_{d:}$ 회절감쇠치, $T L$ : 투과손실치

또한, 공사장 방음시설 설치기준 참고 1.에 제시된 “삽입손실 측정을 위한 측정지점(음원 위치, 수음자 위치)은 음원으로부터 $5 \mathrm{~m}$ 이상 떨어진 노면 위 $1.2 \mathrm{~m}$ 이상 지점으로 하고, 방음벽시설로부터 $2 \mathrm{~m}$ 이상 떨 어져야 하며, 동일한 음량과 음원을 사용하는 경우에 는 기준위치(reference position)의 측정은 생략할 수 있다."의 항목은 다음과 같은 문제가 있다.

이 규정에서는 수음자 위치를 명확하게 규정하지 않고 있다. 따라서 현장에서 작성되어지는 특정공사 신고서에 기록된 계산서를 보면 일반적으로 방음벽 으로부터 $2 \mathrm{~m}$ 이상 떨어진 임의의 지점에서의 삽입손 실을 계산하여 $7 \mathrm{~dB}$ 이상의 삽입손실이 나타나는 것 으로 하여 신고서를 제출하고 있다. 실제로 계산식에 따라 계산하면 방음벽 높이가 $3 \mathrm{~m}$ 일 때 소음원의 위 치가 $50 \mathrm{~m}$ 이상 떨어지더라도 방음벽에서 $2 \mathrm{~m}$ 이격 된 지점에서는 $7 \mathrm{~dB}$ 이상의 삽입손실 효과가 나타나 는 것으로 예측된다. 따라서, 방음시설 설치에 따른 삽입손실 효과를 높이기 위해서는 수음자 위치에 대 한 명확한 규정이 필요하다. 


\section{III. 공사장 방음시설 설치기준 개선방안}

공사장 방음시설 설치기준 현황과 문제점 분석결 과를 토대로 향후 공사장 방음시설 설치에 대한 효율 적인 관리를 위해 다음과 같이 주요 개선방안을 제안 하였다.

\section{1. $3 \mathrm{D}$ 시뮬레이션을 통한 정확한 소음영향 예측 및 방음시설 대책수립}

공사 개시 전 공사 중에 발생될 수 있는 소음에 대 해 $3 \mathrm{D}$ 시뮬레이션 등을 통해 공사장 주변 주거지역과 정온시설인 학교나 축사 등의 피해정도를 예측하여 야 한다. 최근에는 도로나 철도, 공장 등에서의 소음 예측은 $3 \mathrm{D}$ 모델링을 활용하여 현실적인 대안을 제시 하고 있다. 그러나 대부분의 공사장에서는 간단한 예 측식을 사용하여 장비에 대한 소음도를 계산하여 방 음시설의 삽입손실치만 제출한다. 대부분의 공사장 에는 여러 대의 장비가 동시에 가동(운영)되고 있으 며 지형의 형태 및 종류에 따라 소음의 전파감쇠 형 태도 크게 차이가 나타난다. 따라서, 공사장 방음시 설의 삽입손실치는 여러 장비가 동시에 가동(운영)될 때를 산정하여 음원의 위치별로 방음벽 상단 및 측면 회절 등을 고려할 수 있는 예측법인 $3 \mathrm{D}$ 시뮬레이션 기법을 통해 삽입손실치를 예측하여야 한다.

공사 중 소음영향 예측을 한 후에는 생활소음규제 기준을 충족할 수 있는 방음시설 대책을 수립하여 공 사장의 사용 승인 전 지자체에 제출하도록 하여 승인 을 받도록 한다. 이때 투입되는 장비소음은 실측을 하는 것을 원칙으로 하고 소음도 검사를 필한 장비를 사용할 경우에는 검사결과를 활용할 수 있게 한다.

또한, $3 \mathrm{D}$ 시뮬레이션을 활용하여 예측하고 저감방 안을 수립할 때는 환경부고시 제2011-135호 「방음벽 의 성능 및 설치기준」을 적극 활용하여 소음진동기술 사 등의 전문가가 현장조사와 측정 등을 통해 신뢰성 있는 예측자료를 작성하여 제출하는 것이 바람직하다.

\section{3D 시뮬레이션 결과를 반영한 방음시설의 체계 적인 설계}

방음시설을 설계할 때는 정온시설 중 피해가 가장 크게 예상되는 지점을 2지점 이상 수음점으로 선정
하고 공사장에 투입되는 최대장비수와 소음의 영향 을 가장 크게 미치는 작업위치를 음원으로 선정하여 예측하여야 한다. 즉, 음원의 레벨은 투입장비의 최대 수량을 고려하여 각 장비의 파워레벨로 합성소음도를 산출하고 음원의 위치는 현장여건 및 장비의 높이 등 을 고려하여 공사장 부지 내 장비배치 중 정온시설에 대한 소음 영향이 가장 큰 지점을 선정하여야 한다. 방음시설 설치 전 · 후의 성능평가는 피해 예상지점의 부지경계선이나 소음피해가 큰 지점에서 한다.

또한, $3 \mathrm{D}$ 시뮬레이션을 바탕으로 부지경계선 및 건설장비 등에 대한 방음시설의 종류 및 높이, 길이 등을 설계하고 방음벽뿐만 아니라 이동식 방음벽, 방 음커버(Acoustic Enclosure) 등 소음원에 적절하게 적용할 수 있는 방음시설을 사용한다. 공사장과 주거 지역이 근접하여 부지경계선에 설치하는 가설방음벽 의 효과가 제한적일 때는 이동식 방음벽과 방음커버 를 사용하여 설계하고 기준을 초과할 때는 저소음공 법의 적용과 저소음기계의 사용 및 공사장비 투입 대 수 조절 등 다양한 저감방안을 강구해야 한다.

\section{3. 공사장 방음시설 설치기준 변경(안)}

공사장 방음시설 설치기준에 대한 변경(안)을 다음 과 같이 3 가지 (안)으로 제안하고자 한다(Table 4 6).

방음시설의 성능은 크게 두 가지로 구분할 수 있 다. 소음을 얼마나 차단할 수 있는지를 나타내는 기 준인 판넬 자체의 투과손실과 소음피해지점에서 소 음을 얼마나 저감시킬 수 있는지의 삽입손실치로 나 타낼 수 있다. 현재 기준은 삽입손실치에 대한 내용 을 제시하고 있으나 투과손실치에 대한 언급이 없으 므로 이에 대하여 보완하였다. 투과손실치에 대한 것 은 환경부고시 제2011-135호 내용을 따르도록 하여 공사장에 설치하는 방음시설의 성능을 향상시킬 수 있도록 하였다(Table 4).

Table 5, 6에서는 방음시설의 최소높이와 공사장 에 가설되는 방음판넬의 투과손실에 대하여 제안하 였다. 첫째, 방음시설의 최소높이는 현재 $3 \mathrm{~m}$ 이상으 로 제시되어 있으나, 이 기준은 교통소음에 대한 방 음벽 설계시 음원의 높이를 노면 위 $0.5 \mathrm{~m}$ 표준으로 
Table 4. Proposal of installation guide of construction soundproofing facilities(1)

\begin{tabular}{|c|c|c|}
\hline 구 분 & 현행 내용 & 변경내용 \\
\hline 5항 신설 & - & $\begin{array}{l}\text { 설치 전 · 후 전문가가 성능평가를 실시한 평가보고서를 작성하여 지자체에 제출한 } \\
\text { 다. 그 외 방음 패널의 투과손실과 같은 성능 및 설치와 관련된 사항은 환경부고시 제 } \\
2011-135 \text { 호의 내용을 따른다. }\end{array}$ \\
\hline 6항 신설 & - & $\begin{array}{l}\text { 방음시설 설치 전 3D모델 등의 소음 예측식을 활용하여 방음시설 설치 전 · 후의 저 } \\
\text { 감량을 예측하여 방음벽을 설계하고, 방음벽을 통한 저감효과가 없을 때는 저소음공 } \\
\text { 법, 저소음장비사용등의 대책을 수립하여 공사장 사용승인 전 지자체에 제출하여 승 } \\
\text { 인을 받아야 한다. }\end{array}$ \\
\hline 참고 1 & $\begin{array}{l}\text { 삽입손실 측정을 측정은 } \\
\text { 생략 할 수 있다. }\end{array}$ & $\begin{array}{l}\text { 삽입손실 측정을 위한 측정지점은 소음영향이 가장 큰 } 1 \text { 지점 이상으로 하고, 지면 위 } \\
1.2 \mathrm{~m} \sim 1.5 \mathrm{~m} \text { 에서 측정하고 } 2 \text { 층 이상의 경 우는 창문을 열 고 창문바깥쪽으로 } \\
0.5 \mathrm{~m} \sim 1 \mathrm{~m} \text { 이격된 지점에서 측정하고. 방음벽 시설로부터 } 2 \mathrm{~m} \text { 이상 떨어져야 한다. } \\
\text { 동일한 음량과 음원을 사용하는 경우에는 기준위치의 측정은 생략할 수 있다. }\end{array}$ \\
\hline
\end{tabular}

Table 5. Proposal of installation guide of construction soundproofing facilities(2)

\begin{tabular}{|c|c|}
\hline 현행내용 & 변경내용 \\
\hline \multirow{3}{*}{$\begin{array}{l}\text { 1. 방음벽시설 전후의 소음도 차 } \\
\text { 이(삽입손실)는 최소 } 7 \mathrm{~dB} \text { 이상 } \\
\text { 되어야 하며, 높이는 } 3 \mathrm{~m} \text { 이상 } \\
\text { 되어야 한다. }\end{array}$} & $\begin{array}{l}\text { 1. 방음시설의 삽입손실(방음시설 전후의 소음도 차이)은 설치대상지역의 소음목표기준과 } \\
\text { 수음점에 서의 실측치(또는 예측치)와의 차이 이상으로 한 다. }\end{array}$ \\
\hline & 2. 방음시설의 최소높이는 $4 \mathrm{~m}$ 이상 되어야 한다. \\
\hline & 3. 방음시설의 가설방음판넬 투과손실은 $500 \mathrm{~Hz}$ 음에 대하여 $15 \mathrm{~dB}(\mathrm{~A})$ 이상을 표준으로 한다. \\
\hline \multirow{2}{*}{$\begin{array}{l}\text { 참고 } \\
\text { 1. 삽입손실 측정을 측정은 } \\
\quad \text { 생략할 수 있다. }\end{array}$} & $\begin{array}{l}\text { 참고 } \\
\text { 1. 삽입손실 측정을 위한 측정지점(수음점 위치)은 소음의 피해가 우려되는 지점으로 하며 } \\
\text { 동일한 음량과 음원을 사용하는 경우에는 기준위치(reference position)의 측정은 생략할 } \\
\text { 수 있다. }\end{array}$ \\
\hline & 3. 투과손실측정을 위한 측정방법은 KS F 2808에 의한다. \\
\hline
\end{tabular}

Table 6. Proposal of installation guide of construction soundproofing facilities(3)

\begin{tabular}{|c|c|}
\hline 현행내용 & 변경내용 \\
\hline \multirow{2}{*}{$\begin{array}{l}\text { 1. 방음벽시설 전후의 소음도 차이(삽입손실)는 } \\
\text { 최소 } 7 \mathrm{~dB} \text { 이상 되어야 하며, 높이는 } 3 \mathrm{~m} \text { 이상 } \\
\text { 되어야 한다. }\end{array}$} & $\begin{array}{l}\text { 1. 방음시설의 규모는 설치대상지역에서의 소음목표기준을 만족할 수있는 } \\
\text { 크기여야 하며, 방음시설의 최소높이는 } 4 \mathrm{~m} \text { 이상 되어야 한다. }\end{array}$ \\
\hline & $\begin{array}{l}\text { 2. 방음시설의 가설방음판넬 투과손실은 } 500 \mathrm{~Hz} \text { 음에 대하여 } 15 \mathrm{~dB} \text { 이상을 } \\
\text { 표준으로 한다. }\end{array}$ \\
\hline $\begin{array}{l}\text { 참고 } \\
\text { 1. 삽입손실 측정을 측정은 생략할 수 있다. } \\
\text { 2. 그 밖의 경우에 간접법에 따른다. }\end{array}$ & $\begin{array}{l}\text { 참고 } \\
\text { 1. 투과손실측정을 위한 측정방법은 } \mathrm{KS} \mathrm{F} 2808 \text { 에 의한다. }\end{array}$ \\
\hline
\end{tabular}

하였을 때의 기준이다. 공사장의 경우에는 환경부 (2012)에서 고시한「소음발생건설기계 소음도 검사 방법」을 보면, 건설기계 소음도 측정위치를 노면 위 $1.5 \mathrm{~m}$ 와 $0.71 \mathrm{r}(\mathrm{r}$ :측정면의 반경, $\mathrm{m})$ 로 하고 있어 공 사장에서의 주 소음발생원이 노면 위 $0.5 \mathrm{~m}$ 보다 $1 \mathrm{~m}$ 이상 높은 것을 알 수 있다. 이에 따라 공사장에 적용 되는 방음시설의 최소높이가 $4 \mathrm{~m}$ 이상으로 높아져야 할 필요성이 있다.

둘째, 가설방음판넬의 투과손실치는 환경부(2003) 의「건설공사장의 소음관리요령」에 준하며, 방음판넬 을 보통의 상태로 접한한 경우의 투과손실치 $15 \mathrm{~dB}(\mathrm{~A})$ 이상이 될 수 있도록 제안하였으며, 방음시
설의 투과손실을 측정하기 위한 방법으로 $\mathrm{KS} \mathrm{F}$ 2808(2011)을 제시하였다. 이 방법은 잔향실법에 의 한 투과손실 측정방법으로써 인접해있는 2 개의 잔향 실 공통벽에 있는 시료 충진부에 시료를 넣고 한쪽을 음원실, 다른 한쪽을 수음실로 하여 시료의 투과손실 을 측정하는 방법이다.

\section{$\mathrm{IV}$. 결 론}

공사장 소음저감 및 민원해소를 위해 특정공사를 대상으로 의무적으로 설치하고 있는 방음시설이 소 음 피해지역을 고려하지 않은 설치기준과 방음시설 
에 대한 성능평가 규정이 마련되어 있지 않아 공사장 소음 저감을 위한 취지에 부합하지 못하고 있다.

본 연구에서는 공사장 방음시설 설치기준에 대한 문제점을 분석하고 인접해 있는 정온시설에 미치는 소음영향을 최소화하기 위한 공사장 방음시설 설치 기준 개선방안을 다음과 같이 제안하였다.

1) 공사 중에 발생될 수 있는 소음영향 예측 시, $3 \mathrm{D}$ 시뮬레이션을 통한 현실적인 예측방법을 제안 함 으로써 기존의 간단한 예측식으로 공사장 소 음을 예측하던 방식보다 소음예측의 정확도를 높였으 며, 예측결과를 반영한 방음시설의 체계 적인 설계 방안을 제시하였다.

2) 공사장 소음예측 및 저감방안 수립 시, 신뢰성 있 는 예측을 바탕으로 민원과 분쟁예방에 효과 적인 저감방안이 수립될 수 있도록 소음 - 진동 기술사 등의 소음 전문가를 활용한 공사장 현장 조사와 정 확한 소음 실태파악을 제안하였다.

3) 공사장 방음시설 설치기준 변경(안)을 제안하였 다. 주요 내용으로는 환경부가 고시한 「방음시 설 의 성능 및 설치기준과 「건설공사장의 소음 관 리요령」을 따르도록 하여 방음시설의 성능을 향 상시킬 수 있게 하였으며, 방음시설의 성능 지표인 투과손실치에 대한 내용이 설치기준에 는 누락되 어 있어 이를 보완하였다.

이와 같은 방음시설 설치기준 개선방안이 공사장 에 실용적으로 적용된다면 공사장에서 발생하는 소 음을 상당부분 저감할 수 있으며 관련 민원 해소에도 효과적일 것으로 기대한다.

\section{사 사}

본 논문은 환경부 국립환경과학원 수탁과제 「공사 장 소음저감을 위한 관리방안 연구 용역사업의 지원 으로 한국환경정책 - 평가연구원에서 수행한 연구결 과 중 일부임을 밝히며, 업무지원에 감사드립니다.

\section{참고문헌}

국가표준인증종합정보센터, 2011, KS F 2808: 건 물 부재의 공기 전달음 차단 성능 실험실 측 정 방법.

김하근, 2010 , 건설공사장 소음 저감계획 및 방음시 설, 소음 · 진동, 20(4), 13-18.

정일록, 김재용, 윤세철, 이태호, 2012 , 최신 소음 진동 이론과 실무, 신광문화사, 104-106. 환경부, 2003 , 건설공사장 소음관리요령, 14. 환경부, 2006 , 공사장 소음 - 진동 관리지침서, 8. 환경부, 2009 , 공사장 방음시설 설치기준, 소음 진동관리법 시행규칙 별표 10 , 법제처.

환경부, 2009 , 방음시설의 성능과 설치 기준 등, 소 음 · 진동관리법 제 40 조, 법제처.

환경부, 2011 , 방음시설의 성능 및 설치기준, 환경 부고시 제2011-135호, 법제처.

환경부, 2012 , 소음발생건설기계 소음도 검사방법, 환경부 고시, 제2012-186호, 법제처.

최종원고채택 13.08.14 